\title{
Can mean platelet volume be a novel predictive marker in patients with pelvic inflammatory disease?
}

\author{
Ergenekon Karagöz
}

Received: 1 July 2014 / Accepted: 9 August 2014 / Published online: 13 September 2014

(C) Springer-Verlag Wien 2014

\section{Dear Editor,}

In recent issue of ' Wiener klinische Wochenschrift', we have read the article entitled "May Mean Platelet Volume levels be a predictor in the diagnosis of pelvic inflammatory disease (PID)?" by Incebiyik et al. [1] with interest. The authors concluded that mean platelet volume (MPV) values were significantly decreased among patients with PID. To the best of our knowledge, this is the first study assessing the relationship between MPV and PID. We would like to thank the authors for their valuable contribution. On the other hand, we would like to report few concerns about this study from a methodological point of view.

Firstly, the prognosis of PID is associated with chronic and recurring PID, tubal scarring and obstruction, presence of abscesses of the ovaries, fallopian tubes, and other pelvic areas [2]. Additionally, the diagnosis of PID should have been supported with microbiological methods such as gram stain, culture and PCR tests for either N. gonorrhoeae or C. trachomatis. Early evaluation of the disease and prompt treatment may reduce the undesired complications and ameliorate some of the long term sequelae [2]. In this context, the authors could have evaluated their cases according to these parameters that affect disease severity.

Secondly, it was demonstrated that autoimmune disorders, thrombocytopenia, congestive heart failure, acute pulmonary emboli, thyroid functional abnormalities, local or systemic infections, malignancy, inflammatory diseases, and many drugs may potentially affect MPV levels [3]. It would have been better, if the authors had mentioned these other MPV effecting factors while evaluating the associations between MPV and PID.

\section{Dr. E. Karagöz, MD ( $\square)$}

Department of Infectious Diseases and Clinical Microbiology,

GATA Haydarpasa Training Hospital,

34668 Istanbul, Turkey

e-mail: ergenekonkaragoz@hotmail.com
Additionally, the authors did not mention about the type of the tube in which blood tests were performed. As it has been reported earlier in previous studies, MPV levels augment over time in ethylenediaminetetraacetic acid (EDTA) anti coagulated samples $[4,5]$. So, it would have been better, if the authors had made a specific statement about the amount of time that elapsed between taking the blood samples and measuring MPV since any problem and a delay in measurements may affect the MPV values [6].

Lastly, although the findings of the authors were statistically significant, could this parameter be useful in the evaluation of individual patients for diagnosis of PID?

We believe that further research is required to show the relationship between MPV and PID.

\section{References}

1. Incebiyik A, Seker A, Vural M, et al. May mean platelet volume levels be a predictor in the diagnosis of pelvic inflammatory disease? Wien Klin Wochenschr. 2014;126(13-14):422-6.

2. Spencer TH, Umeh PO, Irokanulo E, et al. Bacterial isolates associated with pelvic inflammatory disease among female patients attending some hospitals in Abuja, Nigeria. Afr J Infect Dis. 2014;8(1):9-13.

3. Ceylan B, Mete B, Fincanci M, et al. A new model using platelet indices to predict liver fibrosis in patients with chronic hepatitis B infection. Wien Klin Wochenschr. 2013;125(15-16):453-60.

4. Lancé MD, van Oerle R, Henskens YM, et al. Do we need time adjusted mean platelet volume measurements? Lab Hematol. 2010;16(3):28-31.

5. Varol E, Uysal BA, Ersoy I, et al. Mean platelet volume, an indicator of platelet reactivity, is increased in patients with patent foramen ovale. Blood Coagul Fibrinolysis. 2013;24(6):605-7.

6. Karagöz E, Ulçay A, Turhan V. Mean platelet volume and red blood cell distribution width in prognosis of chronic hepatitis B. Wien Klin Wochenschr. 2014;126(7-8):250-1. 